\title{
Dynamic and Steady-State Analysis of Self-Excited Single-Phase Two-Winding Induction Generators
}

\author{
S. Singaravelu, Ph.D \\ Professor \\ Department of Electrical Engineering \\ Annamalai University \\ Annamalainagar-608 002, INDIA
}

\author{
G. Balasubramanian \\ Assistant Professor \\ Department of Electrical Engineering \\ Annamalai University \\ Annamalainagar-608 002, INDIA
}

\begin{abstract}
This paper presents the dynamic and steady-state analysis of self-excited single-phase two-winding induction generators (SESPIG) used in renewable energy conversions such as wind, small-hydro etc. The conventional dynamic d-q axis model is used to obtain the dynamic characteristics using MATLAB platform. Anew steady-state mathematical model is used to determine the unknown quantities of the equivalent circuit using fuzzy algorithm which avoids the lengthy derivations used so for.Comparison ofthe simulation and experimental results has shownthe satisfactory operation of the SESPIG.
\end{abstract}

\section{Keywords}

Induction-Generator, Renewable-Energy, Single-phase and Fuzzy logic.

\section{INTRODUCTION}

Recently increase in energy demand and limitedenergy sources in the world caused the researchersto make effort to provide new and renewable energysourcesparticularly for rural electrification [1].As per the scenario, in India more than million populations do not have access to electricity. Therefore the available renewable energy sources such as wind, natural gas, bio-gas and rivers with low flow can be utilized for decentralized units. Since the type of loads in remote, hilly and rural areas are mostly single-phase, it is required to generate single-phase electricity[2]. The singlephase induction generators have natural protection against short circuits and have the lowest cost with respect to other generators. Also the induction generator, with its solid rotor easily absorbs these variations and any surge in currents is damped by the magnetization path of its iron core without fear of demagnetization [3]. Single-phase induction generators are now becomingavailable for supplying electrical power to systemdemanding less than $10 \mathrm{KW}$ [4].Therefore two-winding self-excited single-phase induction generators are found to be the best choice for these applications.In this study the dynamic and steady-state characteristics of SESPIG has been discussed. A new steady-state model is developed from the equivalent circuit using nodal analysis. The segregation of real and imaginary parts of the equivalent circuit which is followed so for [5-7] is totally avoided in this model. The model is also flexible wherein any equivalent circuit components can be included or excluded. Fuzzy optimization tool is used to obtain the unknown quantities of the equivalent circuit. The experimental results are compared with the simulation results which show thevalidity of the developed model ofSESPIG.

\section{Mathematical Modeling}

Figure 1 shows the schematic diagram of the two winding single-phase induction generator. The external load is connected to the main winding in series with a capacitor $\mathrm{C}_{\mathrm{se}}$.

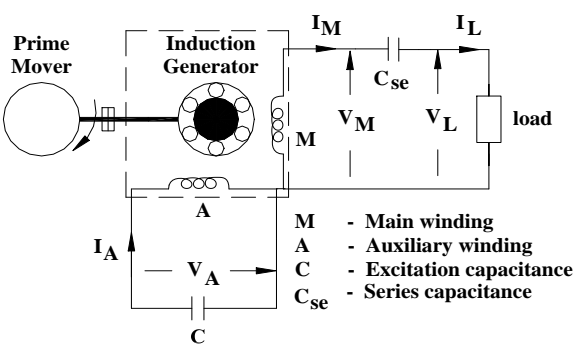

Fig 1: Schematic diagram of capacitor excited two winding single-phase self-excited induction-generator with series compensation

The capacitor $\mathrm{C}_{\mathrm{se}}$ is connected to compensate the demagnetizing effect due to loading. The capacitance $\mathrm{C}_{\mathrm{sh}}$ is connected across the auxiliary winding to provide the excitation current required for the voltage build-up at no-load. The dynamic and steady-state characteristics of SESPIG can be obtained using the $\mathrm{d}-\mathrm{q}$ and steady-state modeling respectively.

\subsection{Dynamic modeling of SESPIG}

The d-q representation of single-phase two-winding inductiongenerator is shown in Figure 2.

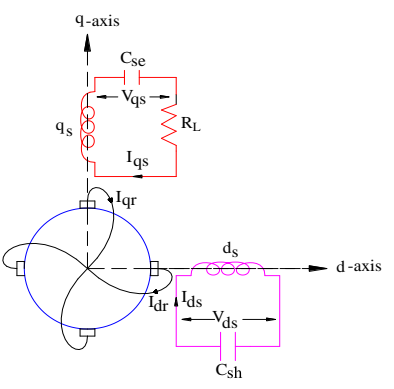

Fig 2: Circuit representation of the single-phase in d-q axes stationary reference frame

The dynamic equations [8] governing the stator and the rotor currents in the stator flux coordinates can be written as follows

$$
\begin{aligned}
& \left(L_{l d s}\right) \frac{d}{d t}\left(i_{d s}\right)=v_{d s}-r_{d s} i_{d s}-\frac{d}{d t}\left(\Psi_{m d}\right) \\
& \left(L_{l q s}+L_{L}\right) \frac{d}{d t}\left(i_{q s}\right)=v_{q s}-r_{q s} i_{q s}-R_{L} i_{q s}-\frac{d}{d t}\left(\Psi_{m q}\right)(2)
\end{aligned}
$$




$$
\begin{aligned}
& \left(L_{l d r}\right) \frac{d}{d t}\left(i_{d r}\right)=v_{d r}-r_{d r} i_{d r}-\frac{d}{d t}\left(\Psi_{m d}\right)-a \omega_{r}\left(L_{l q r} i_{q r}+\right. \\
& \left.\Psi_{m q}\right) \\
& \left(L_{l q r}\right) \frac{d}{d t}\left(i_{q r}\right)=v_{q r}-r_{q r} i_{q r}-\frac{d}{d t}\left(\Psi_{m q}\right)+\frac{\omega_{r}}{a}\left(L_{l d r} i_{d r}+\right. \\
& \left.\Psi_{m d}\right)
\end{aligned}
$$

The state equations of capacitor bank are derived using the dq components of stator voltages as state variables from the Figure 2 .

$\frac{d}{d t}\left(v_{d s}\right)=-\frac{i_{d s}}{C_{s h}}$

$\frac{d}{d t}\left(v_{q s}\right)=-\frac{i_{q s}}{C_{s e}}$

where

$$
\begin{aligned}
& \Psi_{m q}=L_{m q} i_{m q} \Psi_{m d}=L_{m d} i_{m d} \\
& i_{m q}=i_{q s}+i_{q r} i_{m d}=i_{d s}+i_{d r}
\end{aligned}
$$

\subsection{Steady-state modeling of SESPIG}

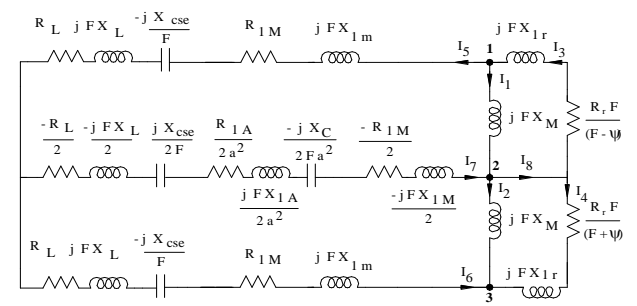

Fig. 3. Equivalent circuit of SESPIG

The steady-state equivalent circuit of SESPIG (Figure 1) is shown in Figure 3.

The parameters of equivalent circuit are:

$$
\begin{aligned}
& \mathrm{Z}_{1}=\mathrm{jFX}_{\mathrm{M}} \\
& \mathrm{Z}_{2}=\mathrm{Z}_{1} \text {; } \\
& \mathrm{Z}_{3}=\mathrm{R}_{2} \dot{\mathrm{F}} /(\mathrm{F}-\mathrm{v})+\mathrm{jFX} \text { Ir } \\
& \mathrm{Z}_{4}=\mathrm{R}_{2} \dot{\mathrm{F}} /(\mathrm{F}+\mathrm{v})+\mathrm{j} F X_{\mathrm{Ir}} \text {; } \\
& Z_{5}=R_{L}+j F X_{L}-\frac{j X_{\text {Cse }}}{F}+R_{1 M}+j F X_{1 M} \text {; } \\
& \mathrm{Z}_{6}=\mathrm{Z}_{5} \text {; } \\
& \mathrm{Z}_{7}=-\mathrm{R}_{\mathrm{L}} / 2-\mathrm{jFX}_{\mathrm{L}} / 2-\frac{\mathrm{jX} \mathrm{Xse}_{\mathrm{Ce}}}{2 \mathrm{~F}}+\mathrm{R}_{1 \mathrm{~A}} / 2 \mathrm{a}^{2}+\mathrm{jFX}_{1 \mathrm{~A}} / 2 \mathrm{a}^{2} \\
& -\mathrm{jX}_{\mathrm{c}} / 2 \mathrm{Fa}^{2}-\mathrm{R}_{1 \mathrm{M}} / 2-\mathrm{jFX} \mathrm{MM}_{1 \mathrm{M}} / 2 \text {; }
\end{aligned}
$$

The branch admittances are:

$$
\begin{aligned}
& \mathrm{Y}_{1}=1 / \mathrm{Z}_{1} ; \quad \mathrm{Y}_{2}=1 / \mathrm{Z}_{2} ; \mathrm{Y}_{3}=1 / \mathrm{Z}_{3} ; \quad \mathrm{Y}_{4}=1 / \mathrm{Z}_{4} ; \\
& \mathrm{Y}_{5}=1 / \mathrm{Z}_{5} ; \quad \mathrm{Y}_{6}=1 / \mathrm{Z}_{6} \text { and } \mathrm{Y}_{7}=1 / \mathrm{Z}_{7} ;
\end{aligned}
$$

Let $\mathrm{V}_{1}, \mathrm{~V}_{2}$ and $\mathrm{V}_{3}$ be the node voltages at nodes 1,2 and 3 respectively. By applying Kirchhoff's current law at node 1

$$
I_{3}=I_{1}+I_{5} \text {; }
$$

Similarly, by applying Kirchhoff's current law at node 2 and node 3 we get Eq. (8) and Eq. (9) respectively

$$
\begin{aligned}
& I_{1}+I_{7}=I_{2}+I_{8} \\
& I_{2}+I_{4}+I_{6}=0
\end{aligned}
$$

where,

$$
\begin{aligned}
& I_{1}=\left(V_{1}-V_{2}\right) Y_{1} ; \quad I_{2}=\left(V_{2}-V_{3}\right) Y_{2} ; \\
& I_{3}=\left(V_{2}-V_{1}\right) Y_{3} ; \quad I_{4}=\left(V_{2}-V_{3}\right) Y_{4} ; \\
& I_{5}=V_{1} Y_{5} ; \quad I_{6}=-V_{3} Y_{6} ; \\
& I_{7}=-V_{2} Y_{7} ; \quad I_{8}=I_{3}+I_{4} ;
\end{aligned}
$$

On substituting Eq. (10) in Equations (7), (8) and (9) and rearranging the resulting equations, we may get the following three node voltage equations.

$$
\begin{aligned}
& V_{1}\left(Y_{1}+Y_{3}+Y_{5}\right)-V_{2}\left(Y_{1}+Y_{3}\right)=0 \\
& \quad-V_{1}\left(Y_{1}+Y_{3}\right)+V_{2}\left(Y_{1}+Y_{2}+Y_{3}+Y_{4}+Y_{7}\right)- \\
& V_{3}\left(Y_{2}+Y_{4}\right)=0 \\
& -V_{2}\left(Y_{2}+Y_{4}\right)+V_{3}\left(Y_{2}+Y_{4}+Y_{6}\right)=0
\end{aligned}
$$

Eqs. (11), (12) and (13) are summarized in matrix form as

$$
\left(\begin{array}{ccc}
\left(Y_{1}+Y_{3}+Y_{5}\right) & -\left(Y_{1}+Y_{3}\right) & 0 \\
-\left(Y_{1}+Y_{3}\right) & \left(Y_{1}+Y_{2}+Y_{3}+Y_{4}+Y_{7}\right) & -\left(Y_{2}+Y_{4}\right) \\
0 & -\left(Y_{2}+Y_{4}\right) & \left(Y_{2}+Y_{4}+Y_{6}\right)
\end{array}\right)\left(\begin{array}{l}
V_{1} \\
V_{2} \\
V_{3}
\end{array}\right)=\left(\begin{array}{l}
0 \\
0 \\
0
\end{array}\right)
$$

Eq. (14) can also be written in short form as

$$
[\mathrm{Y}][\mathrm{V}]=[0]
$$

where $[\mathrm{V}]$ is the node voltage matrix and $[\mathrm{Y}]$ is the nodal admittance matrix.

For successful voltage build up, $[\mathrm{V}] \neq 0$ and therefore from Eq. (15), $[\mathrm{Y}]$ should be a singular matrix i.e., $\operatorname{det}[\mathrm{Y}]=0$. It implies that both the real and the imaginary components of det $[\mathrm{Y}]$ should be independently zero. Therefore to obtain required parameter which results det $[\mathrm{Y}]=0$, fuzzy logic optimization approach is implemented.

\section{Experimental Setup and Machine Parameters}

A single-phase cage induction generator is selected for the test. The view of experimental setup is shown in Figure4. The details of the induction generator is $0.75 \mathrm{~kW}$, 4-pole, 50 $\mathrm{Hz}, 230 \mathrm{~V}, 6$ A, $1500 \mathrm{rpm}$ capacitor start.

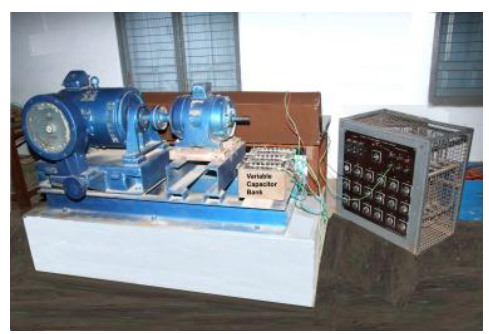

Fig. 4. Experimental setup of single-phase twowinding self-excited induction generator

Base values:

$$
\begin{array}{lll}
V_{\text {base }}=\text { rated voltage } & & =230 \mathrm{~V} \\
I_{\text {base }}=\text { rated current } & & =6 \mathrm{~A} \\
Z_{\text {base }}=V_{\text {base }} / I_{\text {base }} & & 38.33 \mathrm{ohms} \\
\text { Base power } P_{\text {base }}=\mathrm{V}_{\text {base }} * \mathrm{I}_{\text {base }} & & =1.38 \mathrm{~kW} \\
\text { Base speed } N_{\text {base }} & & =1500 \mathrm{rpm} \\
\text { Base frequency } f_{\text {base }} & & =50 \mathrm{~Hz}
\end{array}
$$

The p.u parameters of the machine are:

$$
\begin{array}{ll}
\mathrm{R}_{1 \mathrm{M}}=0.0734, & \mathrm{R}_{2}=0.1036, \quad \mathrm{X}_{\mathrm{IM}}=\mathrm{X}_{\mathrm{lr}}=0.1675, \\
\mathrm{R}_{1 \mathrm{~A}}=0.1357, & \mathrm{X}_{\mathrm{IA}}=0.3074,
\end{array}
$$

The magnetizing reactance $X_{M}$ versus air gap voltage $V_{g} / F$ expressed (in p.u) by a set of piecewise linear approximations are given below.

$$
\begin{array}{ll}
\mathrm{V}_{\mathrm{g}} / \mathrm{F}=1.689-0.2 \mathrm{X}_{\mathrm{M}} & \text { for } \mathrm{X}_{\mathrm{M}} \leq 3.2 \\
\mathrm{~V}_{\mathrm{g}} / \mathrm{F}=2.844-0.555 \mathrm{X}_{\mathrm{M}} & \text { for } \mathrm{X}_{\mathrm{M}}>3.2
\end{array}
$$

\section{Fuzzy optimization for steady-state analysis}

The fuzzy logic process based optimization is applied to obtain det $[Y]=0$. In this the real and imaginary values of the $\operatorname{det}[\mathrm{Y}]$ are calculated and they are introduced separately to the fuzzy logic process. The fuzzy logic process generates the correction of the unknown quantities and they are updated in 
matrix $\mathrm{Y}$ and again $\operatorname{det}[\mathrm{Y}]$ is evaluated, until $\operatorname{det}[\mathrm{Y}]$ reach to desired tolerance value $\epsilon$.

Figure 5 shows the Membership function for input signals $\mathrm{G}_{\text {fuz }}$. The Rule base involves seven rules tallying with seven linguistic variables:

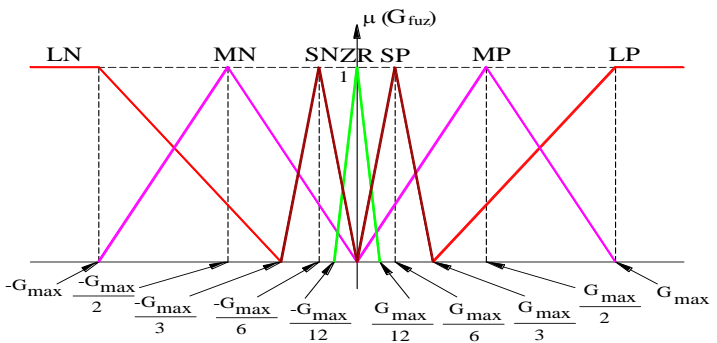

Fig. 5. Membership function for input signals $\mathbf{G}_{\text {fuz }}$.

Rule 1: if $\mathrm{G}_{\text {fuz }}$ is $\mathrm{LN}$ then $\mathrm{H}_{\text {fuz }}$ is $\mathrm{LN}$,

Rule 2: if $\mathrm{G}_{\mathrm{fuz}}$ is $\mathrm{MN}$ then $\mathrm{H}_{\mathrm{fuz}}$ is $\mathrm{MN}$,

Rule 3: if $\mathrm{G}_{\mathrm{fuz}}$ is $\mathrm{SN}$ then $\mathrm{H}_{\text {fuz }}$ is $\mathrm{SN}$,

Rule 4: if $\mathrm{G}_{\mathrm{fuz}}$ is $\mathrm{ZR}$ then $\mathrm{H}_{\mathrm{fuz}}$ is $\mathrm{ZR}$,

Rule 5: if $\mathrm{G}_{\text {fuz }}$ is $\mathrm{SP}$ then $\mathrm{H}_{\text {fuz }}$ is $\mathrm{SP}$,

Rule 6: if $\mathrm{G}_{\text {fuz }}$ is MP then $\mathrm{H}_{\text {fuz }}$ is MP, and

Rule 7: if $\mathrm{G}_{\text {fuz }}$ is LP then $\mathrm{H}_{\text {fuz }}$ is LP

The fuzzy input signals $G_{\text {fuz }}$ is sent to process logic, which generates the fuzzy output signals $\mathrm{H}_{\text {fuz }}$ based on the previous rule base and are represented by seven linguistic variables similar to input fuzzy signals. The output fuzzy signals $\mathrm{H}_{\text {fuz }}$ are then sent to the defuzzification interface. Finally the defuzzifier will transform fuzzy output signals $\mathrm{H}_{\text {fuz }}$ intro crisp values $H$. The centroid-of-area (COA) defuzzification strategy [9] is adapted and the unknown quantities are updated in the matrix $\mathrm{Y}$. The number of triangular fuzzy-membership functions used in this paper and fuzzy rules are selected heuristically to minimize number of iterations required for convergence.Having obtained the det $[\mathrm{Y}]=0$ i.e., when real quantity reached $\mathrm{a} \leq \epsilon$ and imaginary quantity reached $\mathrm{b} \leq \epsilon$ the iteration is terminated and results unknown quantities. A simple computer algorithm can be developed incorporating the above procedure and steady state value of $X_{M}$ and $F$ can be computed for any value of $C, v$ and $\mathrm{R}_{\mathrm{L}}$. Using $\mathrm{X}_{\mathrm{M}}$ and $\mathrm{F}$, air gap voltage $\mathrm{V}_{\mathrm{g}} / \mathrm{F}$ can be found. Once $V_{g} / F, X_{M}$, and $F$ are known, the equivalent circuit is completely solved to yield the steady state performance. Similarly the steady state performance can be found if $\mathrm{X}_{\mathrm{C}}$ and $\mathrm{F}$ are taken as unknown quantities.

\section{Results and Discussion}

Both Dynamic and steady-state analyses of SESPIG areinvestigated with and without series capacitance (in main winding) and the results are presented. The dynamic response to step changes in load and generator voltage, current are examined. On the other hand the steady-state behavior of SESPIG also investigated and the results are presented. In general, it is observed that the series capacitance has self-

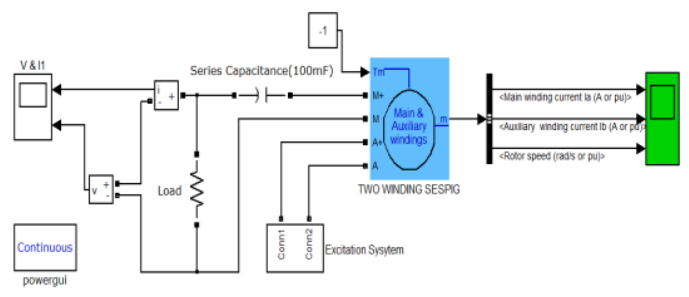

Fig. 6. MATLAB/SIMULINK SESPIG BLOCK regulating characteristics and hence better voltage regulation.

\subsection{Dynamic analysis}

MATLAB/SIMULINK block shown in Figure 6 is used to obtain various dynamic responses. The block contains a selfexcited single-phase two-winding induction generator with excitation provided at the auxiliary winding. The load and series capacitance is provided at the main winding terminals. The dynamic responses of SESPIG is obtained for the following cases
i) No-load voltage build up
ii) Step changes in load without series capacitance
iii) Step changes in load with series capacitance
iv) Short circuit at Load terminals
v) Short circuit across Auxiliary winding terminals

\section{i) No-load voltage build up}

The no load voltage build-up in the main winding is shown in Figure 7. The steady-state terminal voltage at the main winding is $238 \mathrm{~V}$.

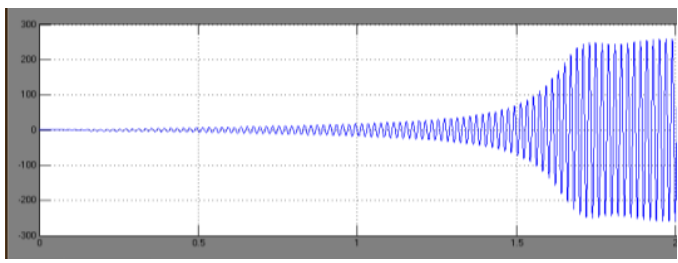

Fig. 7. No load voltage build-up across main winding

ii) Step changes in load without series capacitance The load is applied across main winding in step till rated current is reached. It is observed that when load increases the

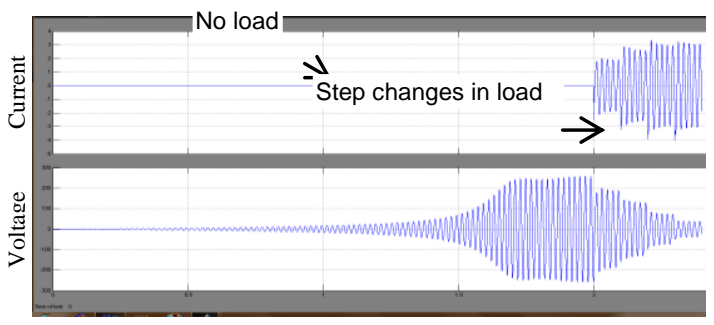

Fig. 8. Load voltage and current across main winding (without series capacitance)

current across main winding increase and the voltage decreases. Since a fixed capacitance is used across the auxiliary winding, the reactive power supplied by this is fixed. The voltage across the main winding can be improved by introducing appropriate series capacitance.

\section{iii) Step changes in load with series capacitance}

In this scheme a fixed capacitance is connected across the auxiliary winding and a series capacitance

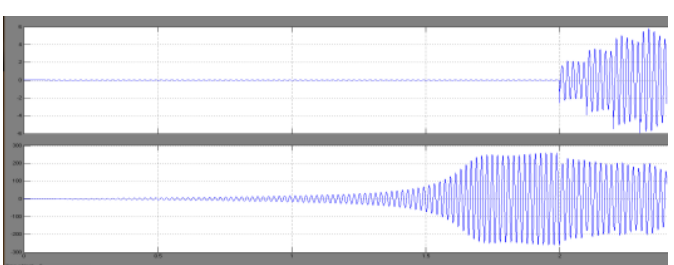

Fig. 9. Load voltage and current across main winding (with series capacitance) 
$\left(\mathrm{C}_{\mathrm{se}}=100 \mu \mathrm{F}\right)$ connected across the main winding. It is observed from the Figure 9 the voltage across the main winding can be improved when compared to Figure 8.

\section{iv) Short circuit at load terminals}

A common type fault that usually occurs is the short circuit across the load terminals. Therefore the response of the main winding voltage and current to sudden short circuit across the load is investigated and is shown in Figure 10.

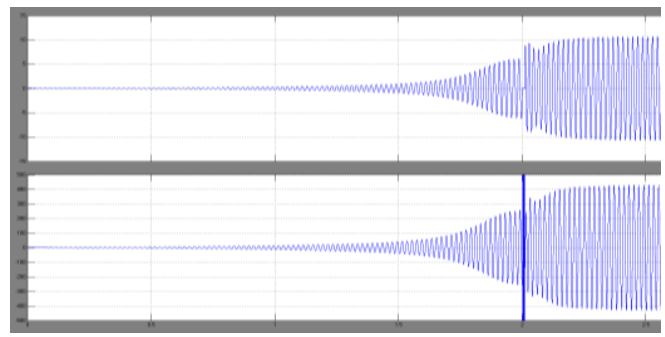

Fig. 10. Short circuit at load terminals (Main winding)

It is observed that generator does not de-excite, but continues to feed the fault. Since the regulating capacitor $\mathrm{C}_{\mathrm{se}}$ will come in parallel to the main winding terminals during the fault, the generators overexcites [8] and increase the generator voltage to $1.83 \mathrm{pu}$. This increased voltage will in turn charge the capacitor to a higher voltage and hence the generator current increased to $1.76 \mathrm{pu}$. Since the rise in magnitude of short circuit is only around $1.76 \mathrm{pu}$, it can be simply avoided by over current protection. Because of the presence of series capacitance it helps to limit the short circuit current, otherwise the short circuit magnitude will be so high.

\section{v) Short circuit acrossauxiliary winding terminals}

Figure 11 shows the case when the SPSEIG supplying load through main winding and short-circuit across the auxiliary winding capacitor $\mathrm{C}_{\mathrm{sh}}$. The voltage and current in the main winding before short circuit, at the time of short circuit and after removal of short-circuit (re-excitation - voltage build up will take place) are shown in Figure 11.

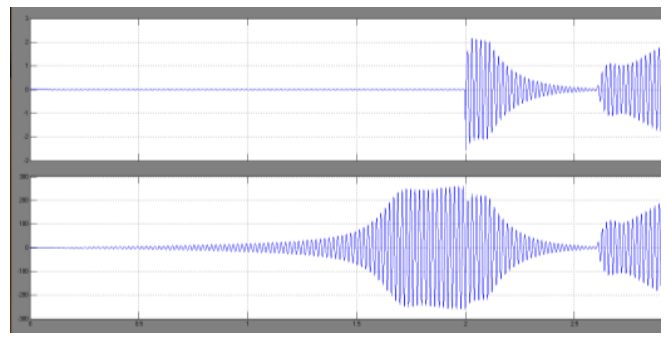

Fig. 11. Short circuit across auxiliary winding terminals and re-excitation on clearance of short circuit

It is observed that after removal of short circuit across the auxiliary winding terminals the generator inherently reexcite due to the availability of residual flux in the magnetic circuit.

\subsection{Steady-state analysis}

The steady-state analysis of the single-phase two winding induction generator is carried out for the following cases

i. No load voltage characteristics under varying speed at different constant capacitance values ii. Performance characteristics of SESPIG without series compensation

iii. Performance characteristics of SESPIG with series compensation

i) No-load voltage characteristics under varying speed at different constant capacitance values

The no load voltage across main winding under varying speed is predicted by using the matrix equation 14 along with fuzzy logic algorithm described in section 4 . Figure 12 shows the variation of no-load terminal voltage with rotor speed for three different values of excitation capacitance.

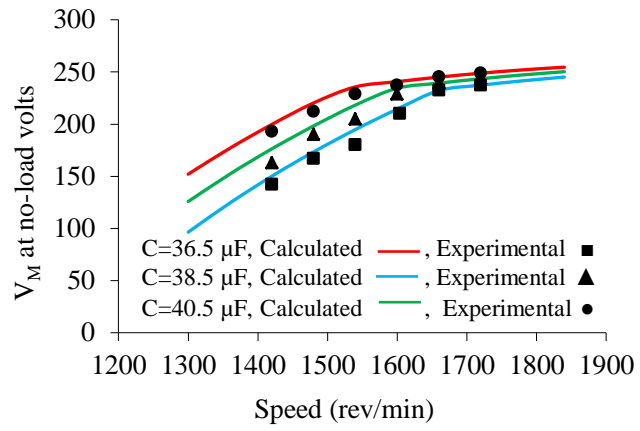

Fig. 12. Variation of no-load voltage with speed

Figure 12 suggest that for successful voltage build-up, the capacitance must exceed some 'threshold' value for a given rotor speed, and the speed must exceed some 'threshold' value for a given value of terminal capacitance. In general, the no-load terminal voltage increases with excitation capacitance and speed, but magnetic saturation as well as the thermal capability of the machine winding will impose an upper limit on the voltage at which the machine can be operated.

ii) Performance characteristics of SPSEIG without series capacitance

Figure 13-15 shows respectively the variations of voltage and current across main winding and auxiliary winding with output power when the generator is excited by three different capacitances and supplying a resistive load, the rotor being driven at rated synchronous speed.

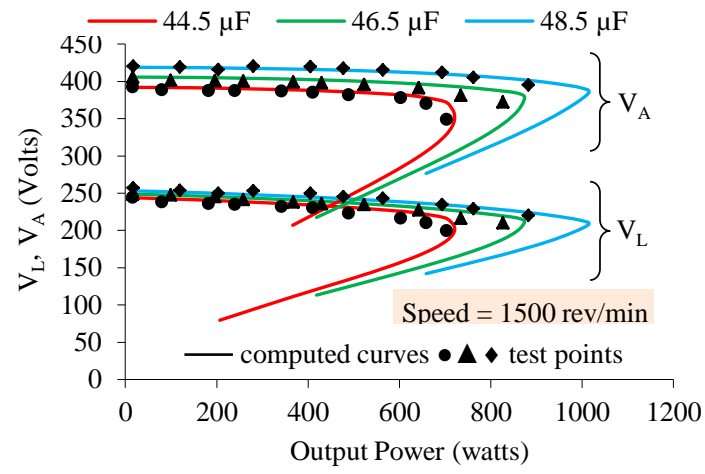

Fig. 13 Load and Auxiliary voltage under varying load

It is evident that an increase in the voltage of shunt capacitance leads to an increase in the power output. However, the voltage regulation remains approximately the same. With the value of $\mathrm{C}$ selected, the voltage in auxiliary windings builds upto $400 \mathrm{~V}(\mathrm{C}=46.5 \mu \mathrm{F})$. Since the current in both windings are still less than the rated current (Figure.14\& Figure.15) it does not affect the safe operation of the machineso for as loading as concerned. 
iii) Performance characteristics of SPSEIG with series capacitance

Although the variable capacitor excitation scheme as discussed in section 5.2 (ii) gives good performance the requirement of a variable capacitor to regulate the terminal

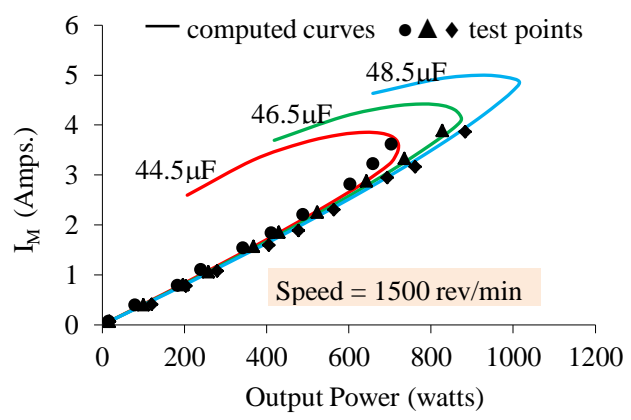

Fig. 14Main winding current under varying load

voltage makes the single-phase SEIG system complex. It restricts the very advantage of recommending the system for small portable power units.

To make the single-phase SEIG system simple and costeffective, an investigation is carried out to study the seriescapacitor excitation on regulating the load terminal voltage of the system. In this analysis capacitance $\left(\mathrm{C}_{\mathrm{se}}\right)$ in series with load (main winding) and a fixed shunt capacitance (C) across auxiliary winding are considered. To predetermine the performance characteristics of single-phase SEIG with series compensation, the same matrix equation (14) can be used.

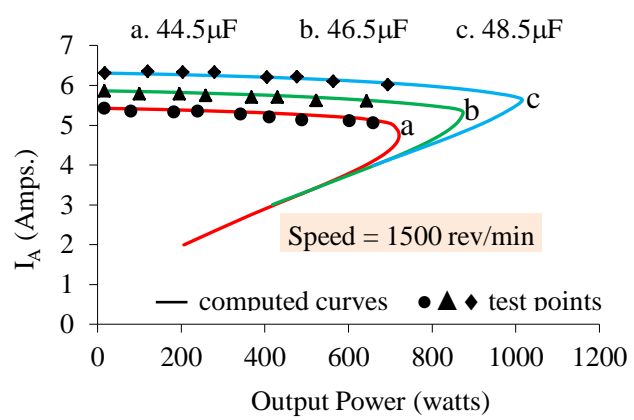

Fig. 15 Auxiliary winding current under varying load

Fig.15-16 has demonstrated the effectiveness of series capacitance in improving the voltage regulation and power output of the two winding single-phase SEIG system at unity power factor load and 0.8 power factor $R$ - $L$ loads. It is evident that the addition of series capacitor of $100 \mu \mathrm{F}$ in main winding

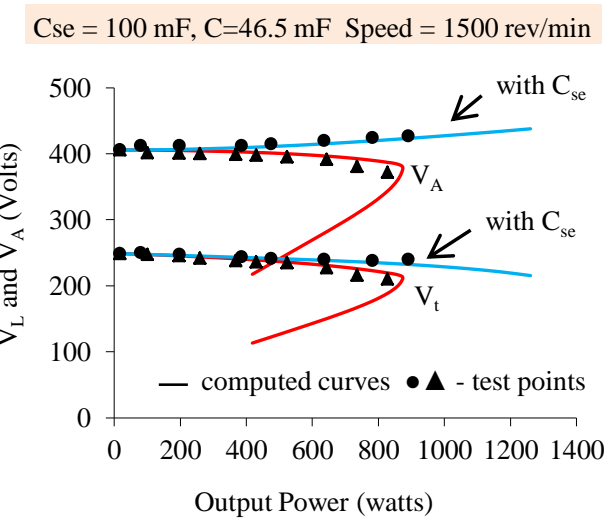

Fig. 16 Auxiliary winding current under varying load and an excitation capacitance of $46.5 \mu \mathrm{F}$ across auxiliary winding improves both the voltage regulation and power output of the SEIG system. The main winding current and

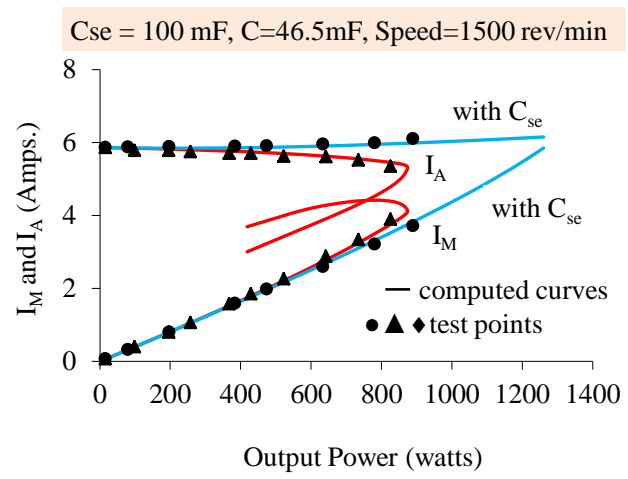

Fig. 17Auxiliary winding current under varying load

frequency are also shown in Fig.16 for 0.8 power factor $R-L$ loads.

Comparison of the results shows that the connection of a series capacitor permits maximum utilization of the generator. The load voltage is self-regulated from no-load to maximum power output in both unity power factor and 0.8 power factor load.

The self-regulating feature of the scheme significantly reduces the cost and complexity of the single-phase SEIG system as it avoids the use of a voltage regulator.

\section{Conclusion}

Dynamic and steady-state analysis of SESPIG is carried out by connecting a shunt capacitanceacross the auxiliary winding and a series capacitance in series with the main winding (short-shunt). The dynamic behavior has been presented under no-load and loading conditions. The main and auxiliary winding should be designed to withstand overvoltage under short circuit at load terminals. The system exhibits inherent protection for short circuit fault in the auxiliary winding and re-excitation takes place after the removal of fault. Proper choice of series and shunt capacitors using the proposed steady state model and fuzzy algorithm explained in this paper results in satisfactory steady state performance of SESPIG. It is observed that series capacitance helps to improve the voltage regulation under varying loads. The satisfactory performance of SESPIG under dynamic and steady state shows the suitability of its applications in wind energy conversion system under isolated operation.

\section{Acknowledgement}

The authors gratefully acknowledge the support and facilities provided by the authorities of Annamalai University, Annamalainagar, Tamilnadu, India to carry out this research work.

\section{References}

[1] S. Unal, M. Ozdemir, S. Sunter, "Voltage and Frequency Control of a Single-Phase Self-Excited Asynchronous Generator", International Aegean Conference on Electrical Machines and Power Electronics (ACEMP), Istanbul-Turkey, May, 2004, pp.509-514.

[2] S.S.Murthy,G.Bhuvaneswari,SarsingGao and Rajesh Kumar Ahuja,"Self Excited Induction Generator for Renewable Energy Application to Supply Single-phase Loads in Remote Locations”, IEEE ,ICSET, 2010. 
[3] Bhaskarapallel,M.GodoySimoes, "Dynamic simulation and analysis of parallel self-excited induction generator for islanded wind farm systems",IEEE Trans. on Industry Application, vol. 41, no. 4,August 2005.

[4] S.S. Murthy, "A novel self-excited self-regulated single phase induction generator," IEEE Trans. on EnergyConversion, vol. 8, no. 3, September 1993, pp. 377-382.

[5] Y.H.A. Rahim, A.I. Aloah, and R.I. AlMudaiheem,"Performance of single-phase induction generator," IEEE Trans. on Energy conversion, vol. 8, no. 3,September 1993, pp. 389-395.
[6] Milan Radic, zoranstajic, Dusanarnautovic, "Critical Speed Capacitive Requirements for SEIG",Automative control and robotics,vol.8.No.1,2009. pp. 165-172.

[7] T.F Chan, "Steady state analysis of self -excited induction generators", IEEE Trans. on Energy conversion, vol. 9, no. 2,June 1994.

[8] Bhimsingh, L.B. Shilpakar, S.S Murthy, A.K. Tiwari, "Improved steady state and transient performance with optimum excitation of single phase self-excited induction generator", Electric machines and power system, 2000.

[9] Timothy and Ross J, Fuzzy logic with engineering applications, McGraw hill international editions, Electrical engineering series, New York, 1997. 